\title{
The Effect of the Infectious Disease Nursing Course on Turkish Students' Knowledge and Attitudes Towards AIDS: A Quasi-Experimental Study
}

\author{
Sibel Şentürk ${ }^{1^{*}}$ (D) Alev Yıldırım Keskin ${ }^{2}$ (D)
}

\begin{abstract}
There is no available treatment or vaccine for HIV/AIDS, and health education has, therefore, become a top priority in the prevention of disease. It is of great importance to have sufficient information about HIV/AIDS and how to control infection. This study was conducted to determine the effect of the Infectious Disease Nursing course on nursing students' knowledge and attitudes towards AIDS.

Materials and Methods. This quasi-experimental study was carried out between February 12 - May 28, 2019 and included 50 nursing students who were taking the Infectious Disease Nursing course for the first time and attended the pre-test and post-test. The data were collected using a Personal Information Form and the AIDS Knowledge and Attitude Scale. Descriptive statistics, the paired sample t-test and Pearson correlation analysis were used in the evaluation of the data.

Results. Among the students who participated in the study, $94.0 \%$ of students were at the age of $18-21$ years; $80.0 \%$ of students were females; $54.0 \%$ of students stated that they had adequate knowledge of AIDS; $78.0 \%$ of students stated that they did not want to provide care to individuals with HIV/AIDS. There was found a significant strong positive correlation between the mean pre- and post-education scores for the AIDS Knowledge and Attitude Scale $(p<0.05, r=0.34 ; p<0.01, r=0.72)$. There was a significant, weak negative correlation between the mean post-education AIDS total Attitude mean score and the status of having contact with a patient with HIV/AIDS and wanting to provide care for a patient with HIV/AIDS ( $<<0.05, r=-0.31)$, and a significant weak positive correlation between the status of wanting to provide care for a patient with HIV/AIDS and seeing people with HIV/AIDS as a threat $(p<0.01 ; r=-0.50)$.

Conclusions. All the students benefited from the information on AIDS and became informed due to attending the Infectious Diseases Nursing course and their attitudes towards AIDS improved.
\end{abstract}

Keywords

Infectious Diseases Nursing; AIDS; Knowledge; Attitude; Student

${ }^{1}$ Department of Nursing, Bucak Health School, Burdur Mehmet Akif Ersoy University, Bucak-Burdur, Turkey

${ }^{2}$ Department of Nursing, Akşehir Kadir Yallagöz Health School, Selçuk University, Akşehir-Konya, Turkey

*Corresponding author: sibelsenturk@mehmetakif.edu.tr

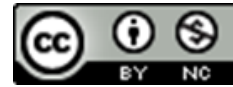

Copyright @Sibel Şentürk, Alev Yıldırım Keskin, 2020

\section{Problem statement and analysis of the latest research}

HIV (human immunodeficiency virus) /AIDS (acquired immunodeficiency syndrome) is a global health problem and remains one of the leading causes of death worldwide. It can be transmitted from person to person, can spread to large numbers of people and has high treatment costs. Its social outcomes are of great importance [1,2]. According to the World Health Organization (WHO) and the Joint United Nations
Programme on HIV/AIDS (UNAIDS), 74.9 million people have been infected with HIV since the beginning of the outbreak and about 32 million have died due to HIV. According to the data from 2018, 37.9 million people worldwide live with HIV; 1.7 million have newly been infected with HIV; 770, 000 people died due to AIDS-related diseases and about 8.1 million people do not know that they have HIV [3]. In Turkey, the first case was reported in 1985 and the official number of cases of HIV reported by June 30, 2019 was 20.202; there were 1, 786 cases of AIDS. It has been reported 
that HIV/AIDS are more common in the 25-29 and 30-34 age groups and that it is transmitted sexually in $49.24 \%$ of cases. The cases reported in 2018 were mostly in the 25 29-year-old age group, and the spread of the disease had increased. The number of HIV-positive people was 676 in 2011 and increased to 3, 678 in 2018. These figures demonstrate just the tip of the iceberg. Turkey has become one of the countries where cases have increased most in the last 10 years [4]. The causes of the increase in the number of HIV-infected cases in Turkey include its location between Asia and Europe, where the spread of HIV is the fastest; its geographic proximity to countries where HIV is prevalent; being on the transit route for drugs from South and Central Asia to Europe; low level of knowledge and awareness about HIV/AIDS and sexually transmitted diseases; an increase in the number of sex workers, especially unregistered ones; a young population (15-49 years); highly mobile population; being a center for tourism; an increase in the abuse of intravenous substances $[5,6]$.

There is no available treatment or vaccine for HIV/AIDS, and health education has, therefore, become a top priority in the prevention of disease. It is of great importance to have sufficient information about HIV/AIDS and how to control infection. In addition, having an increased level of knowledge reduces risky behaviors [7]. University students have been one of the main target groups for prevention and training programs for HIV/AIDS in many countries. It is estimated that in this group of people, who are at the age when many health behaviors are acquired, the number of HIV/AIDS cases will increase exponentially due to the tendency of young people to take risks, decreasing family control, an increased interest in sexual issues, indifference to using protection, and the inadequate number of institutions serving them $[5,8,9]$. Nursing students are in direct contact with blood and bodily fluids during their clinical practice and are the group who will provide health care to individuals with significant infectious diseases such as HIV/AIDS in the future. Therefore, this age group, including nursing students, is among the groups with the highest risk of encountering HIV/AIDS. It is important to evaluate the knowledge and practices of these risk groups and to provide necessary information to prevent the increase of HIV/AIDS cases [10,11]. Insufficient and deficient knowledge of HIV/AIDS among nursing students also has an impact on the knowledge of the communities around them and may cause the emergence of HIV/AIDS-related discrimination and stigmatization. Insufficient HIV/AIDS knowledge in nurses leads to fear, stigmatization and reluctance to provide care to individuals with HIV/AIDS. Increasing the level of knowledge is, thus, an important step in reducing nurse's fear, anxiety, and negative attitudes [12-15].

According to the literature, the nursing students' level of knowledge of HIV/AIDS is not sufficient and they exhibit negative attitudes towards care [8, 12, 13, 15-19]. When nursing students received the education on HIV/AIDS, their knowledge level was found to be increased and they had a pos- itive attitude $[10,11,20-23]$. The decrease in the nursing students' concerns about HIV/AIDS and their positive attitudes led to an increase in their patients' care seeking and treatment compliance, more positive health outcomes, and, thus, an increase in care quality and a decrease in stigmatization $[12,16,17,24]$. This research was carried out to determine the effect of the Infectious Disease Nursing course on nursing students' knowledge and attitudes towards AIDS. We believe that our findings will help provide a basis for further research in this field and provide insight into the inclusion of other nursing schools in their education curricula for HIV/AIDS.

The present study sought answers to the following questions:

1. What was the level of knowledge and what were the attitudes of nursing students toward AIDS before the Infectious Diseases Nursing course?

2. What was the level of knowledge and what were the attitudes of nursing students who took the Infectious Diseases Nursing course toward AIDS?

3. Did the Infectious Diseases Nursing course have an impact on the knowledge and attitudes of nursing students regarding AIDS?

\section{Materials and Methods}

\section{Type of Research}

This quasi-experimental research study was designed as a pretest-post-test study.

\section{Population and Sample of the Research}

The research was conducted between February 12 and May 28, 2019, with second-year nursing students taking the Infectious Diseases Nursing course at the Akşehir Kadir Yallagöz School of Health at Selçuk University in the spring semester of the 2018-2019 academic years. A total of 72 students in the second year of the nursing course participated in the research. Students who: a) were in the second year of study at the nursing department in the spring semester of 20182019 academic year; b) were taking the Infectious Diseases Nursing course; c) had no vision or hearing problems; d) were able and willing to communicate and collaborate; e) agreed to participate in the study; f) participated in the pre-test and post-test stages of the study; g) fully completed the questionnaires were included in the study. A total of 22 students were excluded from the study: 13 students who did not participate in any of the pr-test and post-test and 9 students who incompletely filled in the questionnaire forms. The research was completed with 50 students $(69.44 \%$ of the universe was reached) (Fig. 1).

\section{Data Collection Instruments}

The data were collected by a Student Information Form and the AIDS Knowledge and Attitude Scale for Turkish students [18]. 


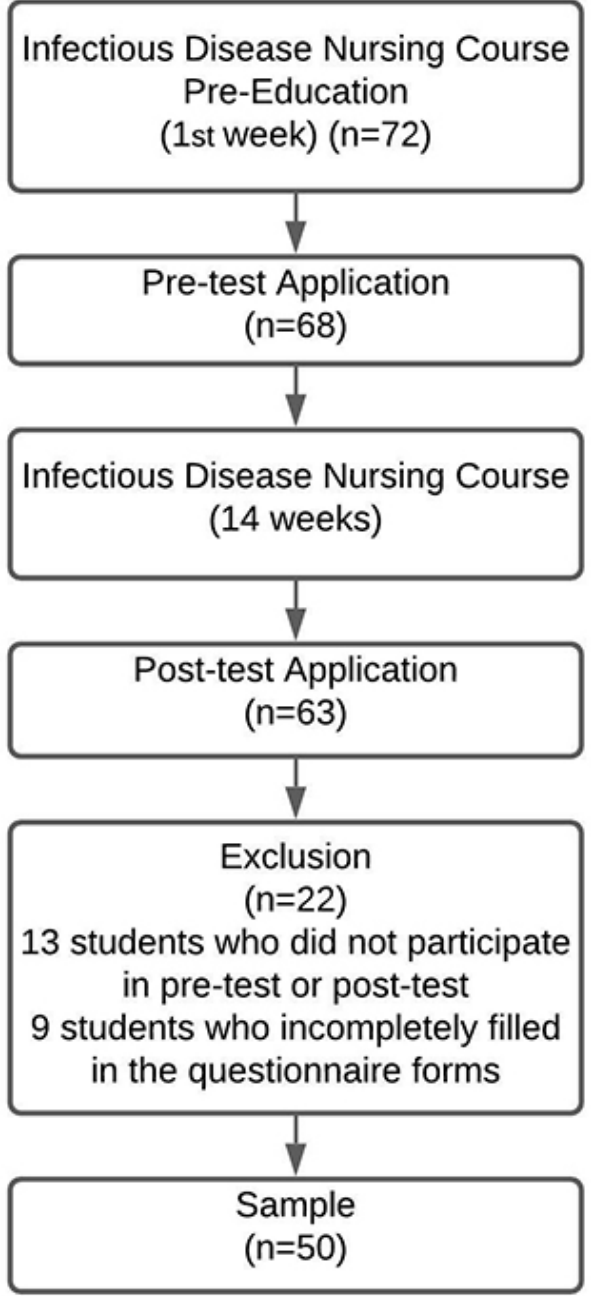

Figure 1. Data collection chart of the study.

\section{Student Information Form}

The questionnaire was prepared by the researchers according to the literature $[5,6,8,9,12-14,16,17]$. The questionnaire consisted of 10 close-ended questions about the students' socio-demographic features (age, gender, school, mother's level of education and employment, father's level of education and employment, economic condition, health insurance, place of family residence) and 7 questions regarding the knowledge and attitude towards AIDS (having adequate knowledge of AIDS, if the answer is "yes" - where he/she got the source of information, perceived people with HIV/AIDS as a threat, contacted a patient with HIV/AIDS during the internship, provided care for a patient with HIV/AIDS during the internship, wanted to provide care to a patient with HIV/AIDS; if the answer is "no" - I don't want to provide care). The questionnaire was pilot tested on a sample group of students $(n=5)$. All questions were clear.

\section{AIDS Knowledge and Attitude Scale}

This scale was developed by Aydemir, Yakın \& Arslan (2018) and consists of two sections: knowledge and attitudes [25]. The section that measures knowledge of AIDS consists of 21 items and the options given for each item are "true", "uncertain" and "false". The scale consists of three subscales: transmission $(13,10,5,4,12,7,17)$, prevention and general information $(1,11,18,21,3,20,6,8,2)$ and treatment $(9,16$, $19,14,15)$. In the section containing questions about knowledge questions $4,5,7,9,10,12,13,14,15,16,17$ and 19 are reverse-coded. In this section, 1 point is given for each correct answer and 0 points are given for each wrong answer and answer displaying uncertainty. A high score obtained for this section indicates that the person is knowledgeable. The second section of the AIDS Knowledge and Attitude Scale, which includes statements about attitudes, has a 5-point Likert type design, and consists of 17 items. The scale consists of two subscales: stigma $(13,12,15,17,1)$ and negative attitudes towards individuals with $\operatorname{AIDS}(8,7,6,9,2,10,11,14,16,4$, $3,5)$. In this section of the scale, which consists of questions regarding attitudes, questions $1,4,5,6,7,8,9,12,13,15$, 16 and 17 are reverse-coded. In this section, 5 points are given for positive answers to the questions and 4, 3, 2 and 1 point (s) are given for the other options, respectively. A high score obtained for this section indicates a positive attitude. In the study conducted by Aydemir et al., Cronbach alpha value was found to be 0.91 [25]. In our study, the value of Cronbach's alpha was found to be 0.80 .

\section{Data Collection}

Data were collected during February 12 - May 28, 2019. Before starting the questionnaire application, all the students were informed about the purpose of the research and their written and verbal consents were obtained. The survey application was said to be voluntary and the students could leave the study whenever they wanted. The questionnaires were applied in the classroom environment at the end of the lesson. The data collection time for each student took approximately 15-20 minutes.

The data collection form was given to the students in two stages. In the first phase, the pre-test data form and the AIDS Knowledge and Attitude Scale were given to the students and the data were collected within the first week of the Infectious Diseases Nursing course. In the second phase, the post-test data form and the AIDS Knowledge and Attitude Scale were given to the students and the data were collected again during the final week of the 14-week Infectious Diseases Nursing course. At both stages, the students were asked to write their numbers on the forms to avoid any confusion.

\section{Content of the Infectious Disease Nursing Course and HIV/AIDS Education Given to Students}

The Infectious Diseases Nursing Course given to students at the School of Health is a 14-week and 2-credit course in the second-year curriculum and is taught by a lecturer. The course covers the definition of infectious diseases, their 
epidemiological and clinical characteristics, prevention of infectious diseases, control and treatment methods and the principles of nursing care. The topics of the course are presented as slides using the Barcovision device. Within the course, two hours were devoted to AIDS. This covered the definition, epidemiology and etiology of HIV/AIDS, transmission routes and prevention methods, groups with a high risk of transmission, diagnosis, classification, signs and symptoms, treatment, aims of treatment, nurse's responsibilities in prevention and treatment, protective measures for patients and personnel, follow-up of the individuals after the contact, and the "World AIDS Day". During the presentations, the students were able to actively participate in the lesson using the question-answer method. After the course, the students were asked to answer questions about its contents in order to evaluate how much they had understood. The course also aimed to teach how to act in various situations that the students may encounter regarding infectious diseases by giving examples from social media tools.

\section{Data Analysis}

Data analysis was performed using SPSS 24.0 (Statistical Package for the Social Sciences, Chicago, Illinois). The sociodemographic data obtained from the first 10 questions in the data collection form, and 7 questions from AIDS knowledge and attitudes were evaluated as percentages. Cronbach's alpha was calculated for the AIDS Knowledge and Attitude Scale. For evaluating the normality of the data distribution, the Shapiro-Wilk test was used. The paired sample t-test was used for dependent groups in the analysis of normally distributed data. The paired sample t-test was used to compare students' knowledge and attitude scores before and after their education about AIDS. Pearson correlation analysis was used to determine the correlation between the mean knowledge and attitude scores before and after AIDS education. A p value of less than 0.05 was considered to be statistically significant.

\section{Ethical Consideration \& Informed Consent}

Before data collection, ethics committee approval was gained from the Ethics Committee of Non-Interventional Clinical Studies of Burdur Mehmet Akif Ersoy University (Decision Number: GO 2019/56). A written permission was obtained from the Director Office of School of Health Sciences. Written consents from the students, who participated in the study, were obtained after reading an informed consent. Permission to use was obtained from the owner of the scale. This study was conducted following the guidelines for Good Clinical Practice of the World Medical Association (WMA), the Declaration of Helsinki.

\section{Results}

The descriptive characteristics of nursing students are presented in Table 1. Among them, 94.0\% of students were at the age of $18-21$ years; $80.0 \%$ of students were females; $50 \%$ of students were Anatolian high school graduates; $80.0 \%$ of students had health insurance; $38.0 \%$ of students lived in the surrounding district (Table 1).

Table 1. Distribution of nursing students by descriptive characteristics.

\begin{tabular}{|c|c|c|}
\hline Descriptive characteristics & $\mathrm{N}$ & $\%$ \\
\hline \multicolumn{3}{|l|}{ Age } \\
\hline Between 18-21 years & 47 & 94.0 \\
\hline 22 years old and more & 3 & 6.0 \\
\hline \multicolumn{3}{|l|}{ Gender } \\
\hline Female & 40 & 80.0 \\
\hline Male & 10 & 20.0 \\
\hline \multicolumn{3}{|l|}{ Graduated school } \\
\hline Health Vocational High School & 7 & 14.0 \\
\hline Anatolian High School & 25 & 50.0 \\
\hline Other & 18 & 36.0 \\
\hline \multicolumn{3}{|l|}{ Mother's level of education } \\
\hline Below primary education & 15 & 30.0 \\
\hline Primary education or higher education & 35 & 70.0 \\
\hline \multicolumn{3}{|l|}{ Mother's employment } \\
\hline Employed & 47 & 96.0 \\
\hline Not employed & 3 & 4.0 \\
\hline \multicolumn{3}{|l|}{ Father's level of education } \\
\hline Below primary education & 7 & 14.0 \\
\hline Primary education or higher education & 43 & 86.0 \\
\hline \multicolumn{3}{|l|}{ Father's employment } \\
\hline Employed & 40 & 80.0 \\
\hline Not employed & 10 & 20.0 \\
\hline \multicolumn{3}{|l|}{ Economic condition } \\
\hline Income is less than expenditure & 10 & 20.0 \\
\hline Income equals expenditure & 34 & 68.0 \\
\hline Income exceeds expenditure & 6 & 12.0 \\
\hline \multicolumn{3}{|l|}{ Health insurance } \\
\hline Yes & 40 & 80.0 \\
\hline No & 10 & 20.0 \\
\hline \multicolumn{3}{|l|}{ Place of family residence } \\
\hline City center & 15 & 30.0 \\
\hline Surrounding district & 19 & 38.0 \\
\hline Village & 16 & 32.0 \\
\hline
\end{tabular}

There were $54.0 \%$ of students who stated that they had adequate knowledge of AIDS; among them, 36.0\% of students stated that they used social media tools as a source of information; $82.0 \%$ of students stated that they perceived people with HIV/AIDS as a threat; $78.0 \%$ of students stated that they did not want to provide care to patients with HIV/AIDS; $82.0 \%$ of students stated that they were afraid of being infected as the reason for not wanting to provide care (Table 2).

When evaluating Table 3, the AIDS Knowledge and Attitude Scale post-test mean scores increased in accordance with the pre-test mean scores, and the difference between them was determined to be significant $(\mathrm{p}<0.05)$. When the students' mean AIDS knowledge subscale scores were compared, the pre-education mean score for prevention and gen- 
Table 2. Distribution of nursing students by the knowledge and attitudes towards AIDS.

\begin{tabular}{lcc}
\hline Knowledge and attitudes towards AIDS & $\mathrm{N}$ & $\%$ \\
\hline Having adequate knowledge of AIDS & 27 & 54.0 \\
Yes & 23 & 46.0 \\
No & 18 & 66.7 \\
\hline If the answer is "yes", where he/she got the source of information & 9 & 33.3 \\
Social media tools (internet, TV, radio, newspapers, articles) & & \\
Other sources (health personnel, friends, relatives, neighbors) & 41 & 82.0 \\
\hline Perceiving people with HIV/AIDS as a threat & 9 & 18.0 \\
Yes & 3 & 6.0 \\
No & 47 & 94.0 \\
\hline Contacting a patient with HIV/AIDS during the internship & 3 & 6.0 \\
Yes & 47 & 94.0 \\
No & & \\
\hline Providing care to a patient with HIV/AIDS during the internship & 11 & 22.0 \\
Yes & 39 & 78.0 \\
No & & \\
\hline Wanting to provide care to a patient with HIV/AIDS & 32 & 82.0 \\
Yes & 4 & 10.3 \\
No & 3 & 7.7 \\
\hline If the answer is "no", I don't want to provide care & & \\
I am afraid of being infected &
\end{tabular}

Table 3. Comparison of the Students;

AIDS Knowledge and Attitude Scales and Sub-Dimension Scores Before and After Education.

\begin{tabular}{|c|c|c|c|c|c|c|}
\hline \multirow{2}{*}{$\begin{array}{l}\text { AIDS Knowledge and Attitude Scale } \\
\text { Features }\end{array}$} & \multicolumn{2}{|c|}{$\mathrm{X} \pm \mathrm{SD}$} & \multicolumn{2}{|c|}{ Min-Max } & \multirow{2}{*}{$\mathrm{t}$} & \multirow{2}{*}{$\mathrm{p}^{*}$} \\
\hline & Pre-test Score & Post-test Score & Pre-test & Post-test & & \\
\hline \multicolumn{7}{|c|}{ Knowledge Sub-Dimension Scores (Min:0, Max:21) } \\
\hline Transmission Subscale $(0-7)$ & $1.48 \pm 2.05$ & $1.22 \pm 1.61$ & $0-6$ & $0-7$ & 0.772 & 0.444 \\
\hline $\begin{array}{l}\text { Prevention and General Knowledge Sub- } \\
\text { scale (0-9) }\end{array}$ & $6.80 \pm 1.52$ & $7.62 \pm 1.39$ & $2-9$ & 4-9 & -4.342 & $<0.001^{*}$ \\
\hline Treatment Subscale (0-5) & $0.72 \pm 0.96$ & $1.10 \pm 1.19$ & $0-3$ & $0-4$ & -2.133 & $0.038 *$ \\
\hline \multicolumn{7}{|c|}{ Attitude Sub-Dimension Scores (Min:17, Max:85) } \\
\hline Stigma Subscale (5-25) & $18.72 \pm 4.00$ & $19.24 \pm 3.46$ & $8-25$ & $10-25$ & -1.078 & 0.286 \\
\hline $\begin{array}{l}\text { Negative Attitude Towards Individuals with } \\
\text { AIDS Subscale (12-60) }\end{array}$ & $31.92 \pm 7.98$ & $35.94 \pm 7.79$ & $12-48$ & $20-58$ & -3.822 & $<0.001^{*}$ \\
\hline $\begin{array}{l}\text { AIDS Knowledge Scale Total Point Aver- } \\
\text { ages }(0-21)\end{array}$ & $9.00 \pm 2.61$ & $9.96 \pm 2.84$ & $5-15$ & $4-21$ & -2.178 & $0.034^{*}$ \\
\hline $\begin{array}{l}\text { AIDS Attitude Scale Total Point Averages } \\
(17-85)\end{array}$ & $50.64 \pm 10.19$ & $55.18 \pm 9.03$ & $22-72$ & $33-75$ & -4.474 & $<0.001 *$ \\
\hline
\end{tabular}

Notes: * paired sample t-test; $\mathrm{p}<0.05 ; \mathrm{X}:$ Mean; SD: Standard Deviation.

eral knowledge subscale and treatment subscale with the posteducation mean score difference between them was found to be statistically significant $(\mathrm{p}<0.05)$, while transmission subscale was not statistically significant $(\mathrm{p}>0.05)$. The students' pre-education mean score on the negative attitude towards individual subscale with the post-education mean score difference between them was found to be statistically significant $(\mathrm{p}<0.05)$, while stigma subscale was not signifi- cant $(\mathrm{p}>0.05)$ (Table 3$)$.

The correlations between the pre- and post-education mean scores from the subscales of the AIDS Knowledge and Attitude Scale are given in Table 4. There was found a significant positive correlation between the pre-education and post-education transmission subscale mean score and the preeducation and post-education total knowledge mean score $(\mathrm{p}<0.001)$. There was a significant strong positive correla- 
tion between the pre-education prevention subscale and total knowledge mean scores $(\mathrm{p}<0.001)$ and the post-education total knowledge mean score $(\mathrm{p}<0.001)$; between the posteducation prevention subscale and knowledge mean scores $(\mathrm{p}<0.001)$. There was a significant strong positive correlation between the pre-education treatment subscale and total knowledge mean scores $(\mathrm{p}<0.001)$ and the post-education treatment subscale mean score $(\mathrm{p}<0.05)$ and a weak positive correlation between the post-education treatment subscale mean score and the pre and post education total knowledge subscale mean score $(\mathrm{p}<0.001)$. There was found a significant strong positive correlation between the pre-education stigma subscale mean score, the pre-education attitude mean subscale, the post-education negative attitude towards individuals with AIDS mean subscale, and the pre-education mean total attitude score and between the post-education stigma subscale mean score, the pre-education total attitude mean score, and the post-education total attitude mean score $(\mathrm{p}<0.001)$. There was a significant positive correlation between the pre-education negative attitude towards individuals with AIDS mean subscale score and the post-education stigma subscale score, the post-education positive attitude towards AIDS subscale score, the pre-education total attitude mean score, and the post-education total attitude mean score and between the post-education negative attitude towards individuals with AIDS subscale mean score and the total pre-education and post-education attitude mean score $(\mathrm{p}<0.001)$. There was also a significant positive correlation between the preeducation and post-education AIDS Knowledge mean scores $(\mathrm{p}<0.05)$ and AIDS Attitude mean scores $(\mathrm{p}<0.001)$ (Table 4).

There was a significant weak negative correlation between the pre-education AIDS Knowledge Scale mean scores and the status of perceiving people with HIV/AIDS as a threat $(\mathrm{p}<0.05)$. There was a significant weak negative correlation between the post-education AIDS Attitude Scale mean scores and having contact with a patient with HIV/AIDS and providing care to a patient with HIV/AIDS ( $p<0.05)$; weak positive correlation between the post-education AIDS Attitude Scale mean scores and perceiving people with HIV/AIDS as a threat $(\mathrm{p}<0.05)$. There was a significant strong positive correlation between the having contact with a patient with HIV/AIDS and status of providing care to a patient with HIV/AIDS ( $\mathrm{p}<0.01$ ); weak positive correlation between the having contact with a patient with HIV/AIDS and wanting to provide care to a patient with HIV/AIDS ( $\mathrm{p}<0.05$ ). There was a significant strong negative correlation between the wanting to provide care to a patient with HIV/AIDS and perceiving people with HIV/AIDS as a threat $(\mathrm{p}<0.05)$ (Table 5).

\section{Discussion}

Today, HIV/AIDS have become a global pandemic and their spread is not yet under control. Due to antiretroviral therapy, HIV is currently defined as a chronic disease. This means that healthcare professionals, particularly nurses, will frequently encounter HIV-infected individuals throughout their professional lives. This obliges all healthcare professionals to have adequate and correct knowledge about HIV/AIDS, and to maintain a professional attitude that is not affected by fears, stigmatization, and misunderstandings about the disease and patients. The spread of HIV/AIDS in a community indicates that individuals in that community have inadequate knowledge of safe-sex practices and the prevention of HIV transmission $[17,21,26]$. For this reason, it is important for community awareness that nursing students have adequate knowledge about HIV/AIDS and positive attitudes towards it. The current study examined the effect of the Infectious Disease Nursing course on nursing students' knowledge and attitudes regarding AIDS with reference to the previous literature. This research found that the nursing students' mean knowledge score was $9.00 \pm 2.61$ before the course and increased to $9.96 \pm 2.84$ after the course; however, although the difference was statistically significant, the knowledge level remained low. Previous studies evaluating the knowledge levels of HIV/AIDS in nursing students have found different mean knowledge scores: it was at a moderate level $(13.76 \pm 2.88)$ in the study conducted by Kök, Güvenç \& Kaplan; at a moderate level among firstyear $(5.07 \pm 1.91)$ and second-year $(5.71 \pm 1.38)$ students and at a high level $(6.72 \pm 1.56)$ in third-year students in the study conducted by Adhikari et al.; at a good level (23.74 \pm 2.47$)$ in the study conducted by Chendake and Mohite; at a moderate level $(13.19 \pm 5.05)$ in the study conducted by Babaoglu, Demir \& Biçer; at a moderate level $(28.99 \pm 7.03)$ in the study conducted by Quzouni and Nakakis [8, 16, 18, 27, 28]. These differences in knowledge levels are thought to have occurred due to different sociodemographic characteristics of the sample groups, training on infectious diseases received by both groups during the applied and theoretical courses, and the impact of the information whether there were HIV/AIDS cases in their countries.

In the study conducted by Diesel, Taliaferro \& Ercole, involving 53 Cameroonian, 31 Honduran and 33 American nursing students to determine the knowledge, attitudes and beliefs about HIV/AIDS, the students were divided into two groups after receiving didactic education and were assessed before the course or workshop, at the end of the program, and 60 days later. The knowledge of AIDS was found to increase especially among American and Cameroonian nursing students; students with personal and professional experience of HIV/AIDS had better knowledge scores after the first test, and the knowledge remained at the post-test [21]. In the study conducted by Nanayakkara \& Choi, there was found a significant improvement in the knowledge of the intervention group as compared to the control group at the end of a 5-week AIDS education program given to nursing students [22]. In the study conducted by Fatimah and Susanti evaluating the effect of HIV elective class on nursing students' attitudes, it was determined that the knowledge level in students who took HIV elective course was higher than that in students who did not attend it and their negative attitude towards individuals 
Table 4. Correlations between the pre- and post-education mean scores from the subscales of the AIDS Knowledge and Attitude Scale (r).

\begin{tabular}{|c|c|c|c|c|c|c|c|c|c|c|c|c|c|c|c|}
\hline & & 1 & 2 & 3 & 4 & 5 & 6 & 7 & 8 & 9 & 10 & 11 & 12 & 13 & 14 \\
\hline 1 & Transmission subscale pre-education & 1 & -0.24 & -0.19 & 0.09 & -0.04 & 0.17 & -0.26 & 0.08 & 0.07 & -0.07 & $0.72 * *$ & 0.01 & 0 & -0.03 \\
\hline 2 & $\begin{array}{l}\text { Prevention and General Knowledge subscale pre- } \\
\text { education }\end{array}$ & & 1 & 0.04 & -0.16 & -0.07 & 0.2 & $0.58 * *$ & 0.2 & -0.08 & 0 & $0.40 * *$ & $0.50 * *$ & -0.12 & -0.02 \\
\hline 3 & Treatment subscale pre-education & & & 1 & 0.05 & -0.14 & -0.05 & -0.04 & $0.34 *$ & 0.08 & -0.12 & $0.54 * *$ & 0.12 & -0.09 & -0.07 \\
\hline 4 & Stigma subscale pre-education & & & & 1 & $0.37 * *$ & -0.17 & 0.01 & 0.07 & 0.59 & $0.40 * *$ & 0.00 & -0.04 & $0.68 * *$ & $0.57 * *$ \\
\hline 5 & $\begin{array}{l}\text { Negative Attitude Towards Individuals with AIDS } \\
\text { subscale pre-education }\end{array}$ & & & & & 1 & -0.11 & -0.09 & -0.15 & $0.42 * *$ & $0.55^{* *}$ & -0.13 & -0.18 & $0.93 * *$ & $0.64 * *$ \\
\hline 6 & Transmission subscale post-education & & & & & & 1 & 0.05 & 0.02 & 0.04 & -0.04 & 0.24 & $0.68 * *$ & -0.16 & -0.02 \\
\hline 7 & $\begin{array}{l}\text { Prevention and General Knowledge subscale post- } \\
\text { education }\end{array}$ & & & & & & & 1 & 0.2 & -0.12 & 0.02 & 0.14 & $0.61 * *$ & -0.06 & -0.02 \\
\hline 8 & Treatment subscale post-education & & & & & & & & 1 & 0.2 & -0.15 & $0.30^{*}$ & $0.49 * *$ & -0.09 & -0.06 \\
\hline 9 & Stigma subscale post-education & & & & & & & & & 1 & 0.16 & 0.04 & 0.06 & $0.56 * *$ & $0.52 * *$ \\
\hline 10 & $\begin{array}{l}\text { Negative Attitude Towards Individuals with AIDS } \\
\text { subscale post-education }\end{array}$ & & & & & & & & & & 1 & -0.1 & -0.07 & $0.59 * *$ & $0.92 * *$ \\
\hline 11 & Pre-education total knowledge mean score & & & & & & & & & & & 1 & $0.34 *$ & -0.1 & -0.07 \\
\hline 12 & Post-education total knowledge mean score & & & & & & & & & & & & 1 & -0.16 & -0.04 \\
\hline 13 & Pre-education total attitude mean score & & & & & & & & & & & & & 1 & $0.72 * *$ \\
\hline 14 & Post-education total attitude mean score & & & & & & & & & & & & & & 1 \\
\hline
\end{tabular}

Table 5. Correlations between the pre- and post-education AIDS Knowledge and Attitude Scale mean scores with the variables related to the disease (r).

\begin{tabular}{|c|c|c|c|c|c|c|c|c|c|}
\hline & & 1 & 2 & 3 & 4 & 5 & 6 & 7 & 8 \\
\hline 1 & Pre-education total knowledge mean score & 1 & $0.34^{*}$ & -0.1 & -0.07 & -0.12 & -0.13 & 0 & $-0.28^{*}$ \\
\hline 2 & Post-education total knowledge mean score & & 1 & -0.16 & -0.04 & -0.02 & -0.03 & 0.14 & 0.11 \\
\hline 3 & Pre-education total attitude mean score & & & 1 & $0.72 *$ & -0.13 & -0.13 & -0.15 & 0.25 \\
\hline 4 & Post-education total attitude mean score & & & & 1 & $-0.31 *$ & $-0.31 *$ & -0.2 & $0.31 *$ \\
\hline 5 & Having contact with a patient with HIV/AIDS & & & & & 1 & $1.00 * *$ & $0.29 *$ & -0.11 \\
\hline 6 & Providing care to a patient with HIV/AIDS & & & & & & 1 & 0.27 & -0.1 \\
\hline 7 & Wanting to provide care to a patient with HIV/AIDS & & & & & & & 1 & $-0.50 * *$ \\
\hline 8 & Perceiving people with HIV/AIDS as a threat & & & & & & & & 1 \\
\hline
\end{tabular}

Notes: $*-\mathrm{p}<0.05, * *-\mathrm{p}<0.01$ 
with HIV remained constant [11]. In the study conducted by Wang et al. in 2002 involving 2, 002 students (1, 001 students in the control group and 1, 001 students in the intervention group) in China, an education program on infectious diseases was applied using various interactive methods. The intervention group was found to have a higher score than the control group in terms of the knowledge of infectious diseases and the difference was statistically significant [23]. In the study conducted by Machowska et al. evaluating the effect of stigma-reduction workshops' on the knowledge and attitude of healthcare providers and students, the knowledge level of nursing students was found to increase from $30 \%$ before the education to $59 \%$ after the education and the difference between the knowledge scores of all study groups was statistically significant [20]. In the study conducted by Ngcobo \& Mchunu evaluating the knowledge of HIV/AIDS in 133 nursing students, the highest level of knowledge was found to be $87.5 \%$ and the lowest one was $54.1 \%$; the education was effective [10]. The current study is consistent with the literature and it was concluded that the Infectious Diseases Nursing course given to students contributed to the increase in their knowledge of HIV/AIDS.

The main transmission routes of HIV/AIDS include homosexual and heterosexual intercourse, blood and blood product transfusion, using virus-infected surgical instruments and syringes in surgery, as well as for circumcision, hair dressing, ear-piercing and tattooing, tissue and organ transplantation, sperm donation, and transmission from mother to baby through the placenta or breast milk. HIV/AIDS are not transmitted by sharing an environment with an individual with AIDS, common use of places such as kitchens, toilets, and bathrooms, or through bloodsucking insects, handshaking, or respiration [29]. Thus, people can protect themselves from HIV/AIDS through precautions such as maintaining a regular and safe sex life, testing blood and blood products before use, and not sharing syringes [17]. As noted, HIV/AIDS are now considered as chronic diseases due to the treatment methods that have been developed in recent years, and individuals can live for many years without succumbing to the disease if they receive the necessary treatment. The way the individuals living with HIV/AIDS are treated is also important for society [29]. In the current study, no difference was found between the transmission subscale mean scores in the students participating before and after education; however, a difference was found between the prevention/general knowledge and treatment subscale mean scores before and after education. A significant positive correlation was found between the posteducation total knowledge mean score and the mean scores for the transmission, prevention/general knowledge and treatment subscales. According to the literature, nursing students had correct knowledge of the transmission routes of HIV/AIDS; the students were uncertain whether it could be transmitted through hugging, toilet seats, towels, kitchenware, washing the clothes of someone with HIV/AIDS, handshaking, working in the same workplace, studying at the same school, and even through mosquito and insect bites. However, in general, nursing students had adequate knowledge of prevention and treatment $[16,30,31]$. The findings of this study are similar to those in the literature and it was concluded that the students' knowledge increased after they had received education about transmission, prevention and treatment. The present study suggests that young nursing students need more specific and detailed education about HIV/AIDS transmission routes. This education is highly important in terms of their learning how to protect themselves while providing patient care and informing others about HIV/AIDS in the future.

Stigma has been one of the major problems that patients with HIV/AIDS have experienced for many years and is still the most serious problem today [32]. Social and cognitive discrimination, which has been called the "Triangle of Denial, Stigma, and Discrimination", can lead to the rapid spread of HIV/AIDS in society [29]. Negative attitudes, prejudices, stigmatization, and social isolation can lead people to engage risky behaviors, prevent patients from being diagnosed, and social fear may increase transmission. Moreover, individuals with HIV/AIDS need to cope with social difficulties they may face regarding employment, housing, education, and accessing other services, as well as safeguarding their physical and psychological health [32]. In the current study, the nursing students' mean attitude score was found to be $50.64 \pm 10.19$ before education and increased to $55.18 \pm 9.03$ after education, indicating their moderately positive attitudes towards peoples with AIDS, and statistically significant difference. The stigma subscale mean score in nursing students was found to be $18.72 \pm 4.00$ before education and increased to $19.24 \pm 3.46$ after education; the difference was not significant. The mean score for the negative attitude towards individuals with AIDS subscale was found to be $31.92 \pm 7.98$ before education and $35.94 \pm 7.79$ after education, and the difference between them was statistically significant. According to the study conducted by Wang et al., the students who received education about infectious diseases, had more positive attitude scores than those who did not [23]. According to the study conducted by Nanayakkara \& Choi, after AIDS education, there was a significant improvement in the scores for the AIDS Attitude Scale and subscales of blame and judgment, attitude towards imposed measures, and comfort when dealing with patients with HIV/AIDS in the intervention group as compared to the control group [22]. In the study conducted by Babaoglu, Demir \& Biçer, the education about AIDS was found to be beneficial for nursing students due to low levels of prejudice, fear and stigmatization against AIDS among nursing students, despite the high levels in society [8]. In the study conducted by Machowska et al., the knowledge level of nursing students was found to increase from $76 \%$ before the education to $82 \%$ after the education [20]. The results of this research are similar to those in the literature and it can be concluded that the Infectious Diseases Nursing course positively contributed to students' attitudes. Nursing students who fight against the stigma of AIDS are known to play a leading role 
in eliminating the stigma and silence about the disease. In this respect, those students who will be future members of the nursing profession have important duties and responsibilities to fulfill.

In the present study, there was found a statistically significant difference between the pre-education AIDS Knowledge Scale mean score of nursing students and perceiving people with HIV/AIDS as a threat. There was found a statistically significant difference between the post-education AIDS Attitude Scale mean score of nursing students and their status of having contact with a patient with HIV/AIDS, providing care to a patient with HIV/AIDS and perceiving people with HIV/AIDS as a threat. There was revealed a significant weak positive correlation between having contact with the patient and wanting to provide care; a significant strong positive correlation between having contact with the patient and providing care to a patient with HIV/AIDS. There was observed a significant strong negative correlation between wanting to provide care and perceiving people with HIV/AIDS as a threat. According to the study conducted by Leyva-Moral et al., the attitudes of the nursing school in Colombia towards individuals with HIV were more positive than those of the nursing faculty in Peru, and the nursing faculties of both countries did not hesitate to physically contact HIV+ patients [19]. According to the study conducted by Suominen et al., $80 \%$ of Russian nursing students did not want to provide care to individuals with HIV/AIDS, the majority of students were afraid of having contact with someone with HIV/AIDS, the students had quite negative attitudes toward providing care and even showed homophobic attitudes, they had a moderate level of knowledge of AIDS. These negative attitudes and low levels of knowledge will directly affect daily nursing activities for people with HIV/AIDS. It is, thus, important to include adequate information about this group of people in nursing education [33]. In conclusion, according to studies conducted, reducing negative attitudes and prejudices towards, and stigmatization of, AIDS patients is possible through educational strategies; the willingness to give care will increase; perceiving these patients as a threat will decrease $[21,28]$. The findings of this study are consistent with the literature and the Infectious Disease Nursing course is thought to have a positive impact on students' contact with patients suffering from HIV/AIDS, their willingness to provide care and their ability to not perceive these patients as a threat.

\section{Conclusions \& Recommendations}

This study found that students' knowledge of AIDS increased and their attitudes towards AIDS improved due to attending the Infectious Diseases Nursing course. University students constitute a high-risk group in society in terms of sexually transmitted diseases, especially HIV/AIDS, and it is extremely important to increase training and services to increase young people's knowledge of sexually transmitted diseases. Detailed content about HIV/AIDS is recommended to be included in the curricula for nursing students, who will eventually work within the health care system and be responsible for the patient care. Different educational techniques including posters, banners, peer training and interactive education methods that can increase student participation should be used, and the number of relevant course hours could be increased. In addition, students' opinions should be sought, and their mistakes should be corrected in order to prevent stigma. Further randomized controlled studies on sexually transmitted diseases are recommended to be conducted, especially those focusing on HIV/AIDS.

\section{Acknowledgements}

The authors would like to thank all the participants.

\section{Conflict of Interest}

The authors declare that no conflicts exist.

\section{Financial Disclosure}

The authors declared no financial support.

\section{References}

[1] WHO. Global health sector strategy on HIV, 20162021 [Internet]. Geneva: WHO Document Production Services; 2016. p. 60. Available from: https://www.who.int/hiv/strategy2016-2021/ghsshiv/en/

[2] Turkish Ministry of Health General Directorate of Public Health. Turkey HIV / AIDS control program (2019-2024) [Internet]. Ankara: Turkish Ministry of Health Publication; 2019. p. 62. Available from: https://www.who.int/hiv/strategy2016-2021/ghsshiv/en/

[3] UNAIDS data 2019 [Internet]. [cited 2020 Sep 1]. Available from: https://www.unaids.org/en/resources/documents/2019/2019UNAIDS-data

[4] Turkish Ministry of Health General Directorate of Public Health. HIV-AIDS Statistics [Internet]. Ankara: Turkish Ministry of Health Publication; 2019. [cited 2020 Sep 1]. Available from: https://hsgm.saglik.gov.tr/tr/bulasicihastaliklar/hiv-aids/hiv-aids-liste/hiv-aids-istatislik.html

[5] Kurt AS, Yilmaz SD. The levels of knowledge and sources of information on HIV/AIDS of university health-science students. J Educ Res Nurs [Internet]. 2012;9(3):47-52. Available from: http://www.kuhead.org/

[6] Demir G, Şahin T. Knowledge of students of Selçuk University about sexually transmitted infections. J DU Health Sci Inst. 2014;4(3):19-24. Available from: https://dergipark.org.tr/en/download/article-file/56576 
[7] Kaya E, Akıllı M, Sezek F. An investigation of high school students' knowledge about HIV/AIDS in terms of different factors. Pamukkale University J Educ. 2010;27:139-145. Available from: https://dergipark.org.tr/tr/pub/pauefd/issue/11116/132936

[8] Babaoglu ÜT, Demir G, Biçer S. Assessment of the knowledge level of students of department of nursing about HIV/AIDS and attitudes toward it. Bozok Med J. 2018;8(1):18-24. Available from: https://dergipark.org.tr/en/pub/bozoktip/issue/36235/408241

[9] Espada JP, Escribano S, Orgilés M, Morales A, Guillén-Riquelme A. Sexual risk behaviors increasing among adolescents over time: comparison of two cohorts in Spain. AIDS Care [Internet]. 2015 Jan 14;27(6):783-788. Available from: https://doi.org/10.1080/09540121.2014.996516

[10] Ngcobo SJ, Mchunu GG. Bachelor of nursing students' HIV and AIDS knowledge in KwazuluNatal province: an evaluation study. Curationis [Internet]. 2019 Jun 10;42(1). Available from: https://doi.org/10.4102/curationis.v42i1.1928

[11] Fatimah V, Susanti H. The effectiveness of HIV elective class on attitudes nursing students toward gay \& HIV clients in Indonesia. Enfermería Clínica [Internet]. 2019 Sep;29:845-849. Available from: https://doi.org/10.1016/j.enfcli.2019.04.127

[12] Esewe ER, Adeyemo FO, Ikedimma OD. Knowledge and attitude of nursing students towards the care of patients living with HIV/AIDS: a case study. Int Res J Public Heal [Internet]. 2017;1:6. Available from: http://doi.org/10.28933/irjph-2017-06-1801

[13] Bommireddy V, Reddy A, Pachava S, Chandu V, Yaddanapalli S, Lodagala A. HIV knowledge, attitude, and practices among nursing students in Guntur city. Journal of Dr NTR University of Health Sciences [Internet]. 2018;7(3):162. Available from: https://doi.org/10.4103/JDRNTRUHS.JDRNTRUHS_11_18

[14] Boakye DS, Mavhandu-Mudzusi AH. Nurses knowledge, attitudes and practices towards patients with HIV and AIDS in Kumasi, Ghana. International Journal of Africa Nursing Sciences [Internet]. 2019;11:100147. Available from: https://doi.org/10.1016/j.ijans.2019.05.001

[15] Chinnasamy L, Muthukrishnan A. Attitude of healthcare students towards HIV/AIDS and people living with HIV in selected dental and nursing colleges at Chennai, India. HIV \& AIDS Review [Internet]. 2020;19(1):43-48. Available from: https://doi.org/10.5114/hivar.2020.93234

[16] Kök G, Güvenç G, Kaplan Z. Nursing students' knowledge, attitudes, and willingness to care toward people with HIV/AIDS. Int J Caring Sci. 2018;11(3):1697-1706. Available from: http://www.internationaljournalofcaringsciences.org

[17] Jain D, Mittal H, Dixit M, Jain J, Sharma S, Khandelwal A, et al. Assessment of knowledge, attitude and practice among B.Sc. Nursing students towards care of HIV/AIDS patients at Geetanjali College of Nursing, Udaipur: a cross sectional study. International Journal Of Community Medicine And Public Health [Internet]. 2018 Mar 23;5(4):1448. Available from: https://doi.org/10.18203/2394-6040.ijcmph20181215

[18] Adhikari K, Gupta N, Koshy AK, Jain VM, Ghimire A, Jnawali $\mathrm{K}$, et al. Knowledge and attitude towards HIV/AIDS amongst nursing students in Nepal. SAARC Journal of Tuberculosis, Lung Diseases and HIV/AIDS [Internet]. 2016 Oct 19;12(1):8-13. Available from: https://doi.org/10.3126/saarctb.v12i1.15936

[19] Leyva-Moral JM, Dominguez-Cancino KA, GuevaraVasquez GM, Edwards JE, Palmieri PA. Faculty attitudes about caring for people living with HIV/AIDS: a comparative study. Journal of Nursing Education [Internet]. 2019 Dec 1;58(12):712-717. Available from: https://doi.org/10.3928/01484834-20191120-06

[20] Machowska A, Bamboria BL, Bercan C, Sharma M. Impact of "HIV-related stigma-reduction workshops" on knowledge and attitude of healthcare providers and students in Central India: a pre-test and post-test intervention study. BMJ Open [Internet]. 2020 Apr;10(4):e033612. Available from: https://doi.org/10.1136/bmjopen-2019033612

[21] Diesel H. Comparison of perceptions of HIV/AIDS between Cameroonian, Honduran and American nursing students after Peerled Education. Archives of Nursing Practice and Care [Internet]. 2017 Jul 5;:057-063. Available from: https://doi.org/10.17352/2581-4265.000027

[22] Nanayakkara GN, Choi E-O. Effectiveness of AIDS education program on nursing students' knowledge and attitudes in Sri Lanka. International Journal of Infectious Diseases [Internet]. 2016 Apr;45:266. Available from: https://doi.org/10.1016/j.ijid.2016.02.593

[23] Wang $M$, Han $X$, Fang $H, X u ~ C$, Lin X, Xia S, et al. Impact of health education on knowledge and behaviors toward infectious diseases among students in Gansu Province, China. BioMed Research International [Internet]. 2018;2018:1-12. Available from: https://doi.org/10.1155/2018/6397340

[24] Alawad M, Alturki A, Aldoghayyim A, Alrobaee A, Alsoghair M. Knowledge, attitudes, and beliefs about HIV/AIDS and people living with hiv among medical students at Qassim University in Saudi Arabia. Int J Health Sci (Qassim) [Internet]. 2017;13(5):22-30. Available from: http://www.ncbi.nlm.nih.gov/pubmed/31501649 
[25] Aydemir N, Yakın I, Arslan HS. Developing AIDS knowledge and AIDS attitude scales and assessing their reliability and validity. Psikoloji Çalışmaları / Studies in Psychology [Internet]. 2018 Jun 1;38(1):73-93. Available from: https://doi.org/10.26650/SP409425

[26] Baytner-Zamir R, Lorber M, Hermoni D. Assessment of the knowledge and attitudes regarding HIV/AIDS among pre-clinical medical students in Israel. BMC Research Notes [Internet]. 2014;7(1):168. Available from: https://doi.org/10.1186/1756-0500-7-168

[27] Ouzouni C, Nakakis K. HIV / AIDS knowledge, attitudes and behaviours of student nurses. Health Sci J. 2012;6(1):129-150. Available from: https://www.hsj.gr/medicine/hiv-aidsknowledge-attitudes-and-behaviours-of-studentnurses.php?aid=5302

[28] Chendake M, Mohite V. Assess the knowledge and attitude of nursing students towards HIV/AIDS. Indian J Sci Res. 2013;4:69-74. Available from: https://www.ijsr.in/upload/1898226711CHAPTER_12.pdf

[29] Aksu O. A special area of discrimination in HIV positive women and working life: a netnography study. J Açıköğretim Pract Res. 2017;3(4):174-186. Available from: https://dergipark.org.tr/en/download/articlefile/403889

[30] Bedre AS, Gheena S. HIV/AIDS - related knowledge and attitudes amongst medical, dental and nursing students of Saveetha University, Chennai. Indian Journal of Public Health Research \& Development. 2020;11(6):108-112. Available from: http://medicopublication.com/index.php/ijphrd/

[31] Ali R. Knowledge and attitude of nursing students about HIV/AIDS in Sohag, Egypt. Journal of High Institute of Public Health [Internet]. 2020 Aug 9;50(2):80-86. Available from: https://doi.org/10.21608/jhiph.2020.106798

[32] Ma H, Loke AY. A scoping review of an HIV/AIDSrelated stigma-reduction intervention for professionals and students from health-related disciplines. International Journal of Sexual Health [Internet]. 2020 Apr 2;32(2):94-129. Available from: https://doi.org/10.1080/19317611.2020.1754317

[33] Suominen T, Laakkonen L, Lioznov D, Polukova M, Nikolaenko S, Lipiäinen L, et al. Russian nursing students' knowledge level and attitudes in the context of human immunodeficiency virus (HIV) - a descriptive study. BMC Nursing [Internet]. 2015 Jan 8;14(1). Available from: https://doi.org/10.1186/s12912-014-0053-7

Received: 2020-09-01

Revised: $2020-10-19$

Accepted: 2020-10-30 